\title{
Short term wear of high Dk soft contact lenses does not alter corneal epithelial cell size or viability
}

\author{
Fiona Stapleton, Suzie Kasses, Shirley Bolis, Lisa Keay
}

\begin{abstract}
Backgroundlaims-Current contact lenses (CLs) when worn on an extended wear basis cause corneal epithelial alterations. The aim of this study was to evaluate changes in corneal epithelial cell morphology and physiology following short term ( 3 months) wear of highly oxygen permeable CLs and to compare this with disposable CLs.

Methods-Subjects were wearers of highly oxygen permeable CLs $(n=11$, wearing CLs on a 30 night schedule), disposable CL users $(n=6$, wearing CLs on a 6 night schedule), and non-CL wearers $(n=20)$. Mean CL wear experience was 3 months. Epithelial cells were harvested using corneal cytology and were stained using acridine orange and ethidium bromide. Epithelial cell size and viability were determined.
\end{abstract}

Results-The majority of epithelial cells recovered were non-viable $(71 \%)$, and the mean longest cell diameter was 38 (SD 8) $\mu \mathrm{m}$. Disposable CLs caused an increase in cell size (42 (7) $\mu \mathrm{m})$ compared with both non-wear (39 (7) $\mu \mathrm{m}, \mathrm{p}=0.01)$ and wear of highly oxygen permeable CLs (37 (10) $\mu \mathrm{m}$, $p=0.0049)$. There was no difference in cell viability between groups.

Conclusions-Extended wear of disposable CLs caused an $8 \%$ increase in cell diameter in harvested corneal epithelial cells following 3 months of CL wear. Cells harvested following 3 months' wear of highly oxygen permeable CLs were indistinguishable from those recovered from non-CL wearers.

(Br F Ophthalmol 2001;85:143-146)

Long term overnight contact lens (CL) wear causes profound changes in corneal epithelial metabolism and physiology. In animal studies these effects manifest as increased corneal epithelial fragility, due to epithelial oedema and loss of desmosomal contacts between cells, and reduced epithelial adhesion, due to a reduction in the number of hemidesmosomes in the basement membrane adhesion complex. $^{23}$ Lens related metabolic changes have manifested as impaired mitosis with lactate accumulation in the anterior chamber. ${ }^{4}$

Studies in humans have demonstrated epithelial thinning and reduced oxygen uptake rate with long term extended lens wear. ${ }^{5}$ More recently, overnight lens wear has been shown to impair epithelial barrier function, measured by an increase in permeability to sodium fluorescein. ${ }^{6}$

Direct evaluation of corneal epithelial cell alterations has been possible using specular and confocal microscopy. Morphological changes following extended wear of hydrogel lenses have included increased corneal epithelial cell size on specular microscopy, ${ }^{78}$ which has been attributed to a prolonged residence time of mature cells on the surface epithelium. Short term wear of disposable hydrogel lenses on a 6 night extended wear schedule has been shown to increase superficial cell area by $28 \%{ }^{9}$ and this effect appears to be proportional to the duration of continuous wear. ${ }^{10}$

Both morphological and metabolic alterations associated with extended wear of hydrogel lenses have been primarily attributed to chronic hypoxia or corneal acidosis and, perhaps secondarily, to factors such as reduced tear exchange, mechanical effects, and the impact of the closed eye environment. While the recent introduction of highly oxygen permeable CLs has reduced overt clinical signs of hypoxia in premarket studies, ${ }^{11}{ }^{12}$ it is not clear whether this will reduce the morphological effects of extended wear on the corneal epithelium.

This study aimed to evaluate alterations in epithelial physiology with short term wear of high and low oxygen transmissibility CLs using corneal cytology to harvest superficial epithelial cells. Cell size and cell viability in lens wearers were evaluated and compared with these variables in non-lens wearers.

\section{Methods}

SUBJECTS

Seventeen contact lens wearers were recruited, of whom 11 were participants in a study evaluating the ocular response and lens performance with highly oxygen permeable CLs (lotrafilcon A, Focus Night \& Day, Ciba Vision, Atlanta, GA, USA). These subjects wore lenses on a continuous wear basis for 30 nights and replaced their lenses monthly. The remaining six wearers wore disposable CLs (etafilcon A, Acuvue, Vistakon, Johnson \& Johnson, Jacksonville, FL, USA) on a 6 night extended wear schedule and replaced their lenses weekly. Twenty non-contact lens wearing subjects were also concurrently recruited. Subject demographics and lens wearing details are shown in Table 1.

No subjects had prior experience of lens wear before enrolment in this study. The investigation was conducted in accordance with the
Accepted for publication 9 August 2000 
Table 1 Subject demographic and lens wearing data

\begin{tabular}{llll}
\hline & $\begin{array}{l}\text { Non-contact lens } \\
\text { wearers }(n=20)\end{array}$ & $\begin{array}{l}\text { High Dk lens wearers } \\
(n=11)\end{array}$ & $\begin{array}{l}\text { Low Dk lens wearers } \\
(n=6)\end{array}$ \\
\hline Age (mean (SD)) & $27(5)$ & $36(10)$ & $32(5)$ \\
Males:females & $3: 17$ & $3: 8$ & $4: 2$ \\
Wear schedule & None & 30 nights & 6 nights \\
Wear experience (mean (SD)) & None & $3(1)$ months & $3(1)$ months \\
Lens parameters & NA & 140 & 28 \\
Dk & & $-3.25(0.93)$ & $-2.50(1.96)$ \\
Rx (mean (SD)) & & $8.60 / 14.00$ & $8.80 / 14.00$ \\
BOZR/TD & & 0.065 & $0.087 \mathrm{~mm}$ \\
Mean CT at -3.00DS & $21 \%$ & $55 \%$ \\
Water content & &
\end{tabular}

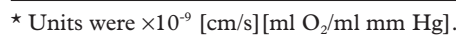

tenets of the Declaration of Helsinki and written consent was obtained following explanation of the study procedures. The University of New South Wales ethics committee approval for the procedures was obtained before the investigation. All subjects underwent full ocular examinations before enrolment and all were in good general health, taking no systemic or topical medications, had no anterior segment pathology, and had normal visual acuity.

\section{SAMPLE COLLECTION}

Contact lens cytology was performed immediately following habitual lens removal at the 3 month aftercare visit and before slit lamp examination. To determine the physiological cell size distribution frequency non-contact lens wearers were sampled on five separate occasions. Contact lens wearers were sampled on a single occasion for comparison. Sample collection was performed 1-2 hours after waking, since a diurnal variation in cell recovery using this technique has been previously demonstrated, ${ }^{13}$ with the highest cell recovery in the early morning.

The mean lens wear experience in both lens wearing groups was 3 (SD 1) months at the time of sample collection. A new disposable contact lens (etafilcon A, Acuvue, Johnson \& Johnson, Jacksonville, FL, USA, 8.80/14.00 $-3.00 \mathrm{DS}$ ) was inserted directly onto the corneal apex with minimum manipulation. The lens was worn for 2 minutes and removed from the cornea using sterile gloves. The lens was everted onto the $5 \mathrm{~mm}$ radius tip of a glass rod and the back (inner) surface of the lens was irrigated using $10 \mathrm{ml}$ of Dulbecco's saline (137 $\mathrm{mM} \mathrm{NaCl}, 2.7 \mathrm{mM} \mathrm{KCl}, 6.5 \mathrm{mM} \mathrm{Na} \mathrm{HPO}_{4}$, $1.5 \mathrm{mM} \mathrm{KH}_{2} \mathrm{PO}_{4}, 0.90 \mathrm{mM} \mathrm{CaCl}, 0.5 \mathrm{mM}$ $\mathrm{MgCl}_{2}, \mathrm{pH} 7.4$ ) through a 21 gauge needle, to remove adherent cells. On two occasions the lens was subsequently stained with a modified Wright-Giemsa stain (Diff-Quik, Bacto Laboratories, Liverpool, NSW, Australia), destained using $70 \%$ methanol and the back surface viewed using light microscopy to ensure that all adherent cells were removed by the rinsing procedure.

\section{SAMPLE PROCESSING}

The cell suspension was stained with ethidium bromide (at a final concentration of $17 \mu \mathrm{M}$ ) and with acridine orange (at a final concentration of $5 \mu \mathrm{M}$ ), incubated in darkness at $37^{\circ} \mathrm{C}$ for 20 minutes. The stain component concentrations were initially optimised for contrast and minimal background fluorescence by titra- tion using live and heat killed bovine corneal epithelial cells. Acridine orange is a fluorophore which intercalates with double stranded nucleic acids in viable cells and fluoresces green, whereas ethidium bromide fluoresces red. ${ }^{14}$ Ethidium bromide is excluded from cells with an intact nuclear membrane, so nonviable cells can be recognised by their red nuclei and viable cells by their green nuclei. Recently rendered non-viable cells are distinguished by their diminished intracellular esterase activity in the cytoplasm.

The suspension was filtered through an $8 \mu \mathrm{m}$ pore diameter polycarbonate filter (Millipore, Bedford, MA, USA) and the filter was mounted on a glass slide and coverslipped. Cells were viewed using fluorescent microscopy at a wavelength of $485 \mathrm{~nm}$ and magnification of $500 \times$.

Cell viability was determined and counts were made of viable and non-viable cells in each sample. The longest cell dimension was measured for each cell using a calibrated eyepiece graticule. This measure correlates highly with cell area. ${ }^{15}$

\section{DATA ANALYSIS}

Differences between cell counts in the different groups were analysed using a Kruskal-Wallis non-parametric ANOVA and a parametric one way ANOVA was used to compare cell size. Multiple range testing was used where indicated. Differences in cell size between viable and non-viable cells overall were evaluated using a grouped $t$ test. Associations between cell count and the time since the lenses were last removed were evaluated using a Spearman's correlation test.

\section{Results}

\section{GENERAL RESULTS}

The majority of cells recovered from all samples were non-viable ( $71 \%$, range $65-75 \%)$ and apoptotic cells were not visualised morphologically in this assay. In general, sloughed cells were polygonal and were found in isolation rather than in clumps. Non-viable cells were slightly but not statistically significantly larger (39 (SD 10) $\mu \mathrm{m}$ ) than viable cells (36 (9) $\mu \mathrm{m}, \mathrm{p}>0.05)$.

The frequency histogram of cell size for the normal non-contact lens wearing subjects summed over five occasions did not follow a normal distribution (Fig 1). The distribution was slightly skewed towards smaller cell sizes for total, live and dead cells with a mean overall size of 37 (11) $\mu \mathrm{m}$ and median $39 \mu \mathrm{m}$ $(12-78 \mu \mathrm{m})$.

\section{CELL SIZE}

There were significant differences in cell size between the three groups (Table 2, p<0.001). Cells harvested from the 6 night disposable contact lens wearing group were significantly larger $(42(7) \mu \mathrm{m})$ than cells recovered from non-wearers (39 (7) $\mu \mathrm{m}, \mathrm{p}=0.01)$ and highly oxygen permeable lens wearers $(37$ (10) $\mu \mathrm{m}$, $\mathrm{p}=0.0049$ ). Differences in cell size between non-wearers and highly oxygen permeable lens 


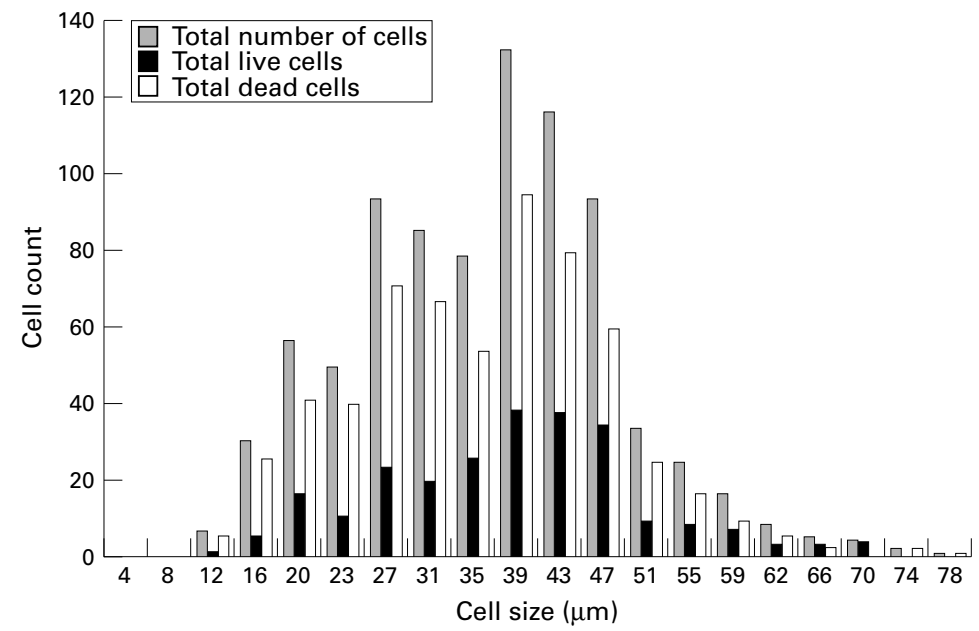

Figure 1 Distribution of cell size for non-contact lens wearers. Distributions are shown for viable, non-viable and total cells.

Table 2 Cell size differences between contact lens wearing and non-contact lens wearing groups

\begin{tabular}{llll}
\hline & $\begin{array}{l}\text { Non-contact lens } \\
\text { wearers }(n=20)\end{array}$ & $\begin{array}{l}\text { High Dk lens wearers } \\
(n=11)\end{array}$ & $\begin{array}{l}\text { Low Dk lens wearers } \\
(n=6)\end{array}$ \\
\hline Total cells recovered & 255 & 188 & 90 \\
Mean $(\mathrm{SD})$ cell size $(\mu \mathrm{m})$ & $37(7)$ & $37(10)$ & $42(7)$ \\
\hline
\end{tabular}

ANOVA $p<0.001$

Low Dk lens wearers $v$ high Dk lens wearers $\mathrm{p}=0.0049$.

Low Dk lens wearers $v$ non-wearers $\mathrm{p}=0.01$.

Table 3 Total, viable and non-viable cell counts between groups

\begin{tabular}{|c|c|c|c|}
\hline Non-contact lens wearers $(n=20)$ & $\begin{array}{l}\text { High Dk lens wearers } \\
(n=11)\end{array}$ & $\begin{array}{l}\text { Low Dk lens } \\
\text { wearers }(n=6)\end{array}$ & \\
\hline Median viable cell count (range) & $2(0-6)$ & $2(0-6)$ & $3(0-8)$ \\
\hline Median non-viable cell count (range) & $13(0-41)$ & $11(2-22)$ & $14(6-36)$ \\
\hline Median total cell count (range) & $14(0-42)$ & $13(2-24)$ & $17(6-40)$ \\
\hline
\end{tabular}

ANOVA $\mathrm{p}>0.05$ for each cell type.

wearers were not statistically significant $(\mathrm{p}>0.05)$.

CELL VIABILITY

There were no significant differences in either the cell counts or the ratio of viable to non-viable cells between the three groups (Table 3). There was no association between cell count and the time since the lenses were last removed for either lens wearing group.

\section{Discussion}

Corneal epithelial cells recovered on contact lens cytology following 3 months of extended wear of highly oxygen permeable CLs are indistinguishable in size, morphology, and viability from cells recovered from non-contact lens wearers. In contrast, 3 months of extended wear of low oxygen permeable lenses results in a significant increase in cell diameter of $8 \%$ compared with both non-wearers and wearers of highly oxygen permeable lenses. Longest cell diameter has been previously shown to correlate highly with cell area ${ }^{15}{ }^{16}$ and based on their published regression, a cell size of 42 (SD 7) $\mu \mathrm{m}$ would be expected to have an area of 891 $\mu \mathrm{m}^{2}$. This calculated increase in area is similar to a previous report showing increased cell area (820 (99) $\mu \mathrm{m}^{2}$ ) after 3 months of extended wear with weekly disposable lenses. ${ }^{10}$ Tsubota et al measured cell size by specular microscopy, and those values might be expected to be smaller than values measured for shed cells, since surface cells in vivo may be partly obscured by neighbouring cells. ${ }^{17}$

The increased cell size in these wearers was not accompanied by any measured alteration in either cell morphology or viability characteristics. Increased cell size following long term overnight wear has been attributed to: impaired basal cell mitosis ${ }^{4}$ and a prolonged residence time of mature cells at the superficial surface, ${ }^{7}$ protection of the ocular surface from the normal shearing force of the lid, ${ }^{18}$ reduced tear exchange preventing the removal of exfoliated cells, ${ }^{7}$ and impaired desquamation. ${ }^{10}$ Protection of the ocular surface from the normal shearing force of the lid is likely to be similar in both groups of lens wearers and while the lid/ocular surface interaction during blinking is likely to be a major force in cell shedding in the non-lens wearer, ${ }^{18}$ the larger cell size in low Dk lens users would suggest that this is not the primary factor driving shedding in the lens wearing eye.

Similarly, tear exchange in lens wearers is around $50 \%$ of that seen in the absence of lens wear ${ }^{19}$ and the lack of significant differences in cell size between wearers of highly oxygen permeable lenses and non-wearers would suggest that impaired tear exchange is not a major factor.

Hypoxia suppresses cell metabolic activity and in the corneal epithelium could potentially cause both slowed mitosis and reduced desquamation. However, in studies using corneal organ culture models, hypoxia causes an initial slowing of desquamation; however, the shedding rate returns to basal levels 2 hours after the onset of hypoxia. ${ }^{20}$ Clearly, mechanisms other than acute hypoxia contribute to cell shedding. The effects of chronic hypoxia on the cornea are less well documented, although indirect effects including epithelial thinning, ${ }^{5}$ increased corneal epithelial cell size, ${ }^{7}$ altered ion transport mechanisms ${ }^{21}$ and altered metabolic enzyme levels in tears ${ }^{22}{ }^{23}$ have been attributed to hypoxia and/or corneal acidosis. There is a considerable difference in oxygen transmissibility between the two lens types worn in this study of approximately fivefold, which appears to be sufficient to prevent alterations in corneal epithelial cell size within the first 3 months of continuous wear in highly oxygen permeable lens wearers. In addition, the highly oxygen permeable lenses were worn on a 30 night continuous wear basis, in contrast with the disposable lens wearing group, who wore lenses on a 6 night continuous basis. The disposable lens wearers would have the advantage of four lens-free nights per month compared with 1 night for the highly oxygen permeable wearers.

The non-lens wearing population sampled in this study were significantly younger than the wearers of highly oxygen permeable lenses $(p<0.005)$; however, corneal epithelial cell size was similar in these groups. Corneal epithelial metabolism has been shown to reduce with age; however, increased cell size or reduced cell 
shedding with age has not been consistently demonstrated. ${ }^{8} 9$

The size frequency profile of cells shed in non-contact lens wearing eyes is consistent with previous observations, ${ }^{15}$ as is the finding that $70 \%$ of the cells recovered using this technique are non-viable. ${ }^{24}$ Cell shedding has been attributed to two distinct mechanisms in the rabbit cornea-namely, terminal differentiation and apoptosis. ${ }^{25}$ Cells shed through terminal differentiation represent the non-viable population as identified here. Apoptotic cells are likely to be smaller, viable cells, showing distinct morphological and biochemical changes. In the present study, apoptotic cells were not visible morphologically, and there were no statistically significant differences in cell size between viable and non-viable cells. However, the presence of a second peak at 27 $\mu \mathrm{m}$ (Fig 1) may suggest that apoptotic cells form part of the shed cell population ${ }^{15}$ and that more specific staining or immunohistochemical labelling techniques are required to confirm whether apoptosis is occurring and whether contact lens wear modulates this.

A wide range of cell types derived from the ocular surface are collected using contact lens cytology. These include corneal epithelial cells, conjunctival epithelial cells and inflammatory cells. Epithelial cells harvested by this technique have been shown using immunohistochemical staining to be mature corneal epithelial cells, which express corneal epithelial basic keratin $(\mathrm{K} 3){ }^{26}$

Contact lens cytology with viability or immunohistochemical staining provides a sensitive technique capable of demonstrating subtle differences in epithelial physiology in the absence of overt clinical signs. This may prove to be useful in monitoring the effects and recovery from lens wear and ocular surface disease or in refractive surgery.

The authors would like to thank Professor Deborah Sweeney, director of clinical research and Dr Isabelle Jalbert at CCLRU/
CRCERT for the organising and planning of clinical studies CRCERT for the organising and planning of clinical studies
from which high Dk and low Dk patients were derived. Jason from which high Dk and low Dk patients were derived. Jason Kasses, Karen Chung, Karen Lee, and Adrene Goh for their help with data collection, also Professor Graeme Wilson for helpful discussions and Professor Brian Brown for manuscript review. The study was partly supported by the Australian Federal Government and by CIBA Vision through the Cooperative Research Centres Programme.

1 Bergmanson JPG, Ruben M, Chu LW. Corneal epithelial response of the primate eye to gas permeable corneal contact lenses. A preliminary report. Cornea 1984;3:10-15.
2 Madigan MC, Holden BA, Kwok LS. Extended wear of contact lenses can compromise corneal epithelial adhesion. Curr Eye Res 1987;6:1257-60.

3 Madigan MC, Holden BA. Reduced epithelial adhesion after extended contact lens wear correlates with reduced hemidesmosome density in cat cornea. Invest Ophthalmol Vis Sci 1992;33:314-23.

4 Hamano H, Hori M, Hamano T, et al. Effects of contact lens wear on mitosis of corneal epithelium and lactate content in aqueous humor of rabbit. $\mathcal{F p n} \mathcal{F}$ Ophthalmol 1983;27: 451-8.

5 Holden BA, Sweeney DF, Vannas A, et al. Effects of long term contact lens wear on the human cornea. Invest Ophthalmol Vis Sci 1985;26:1489-501.

6 McNamara NA, Polse KA, Fukunaga SA, et al. Soft lens extended wear affects epithelial barrier function. Ophthalmology 1998;105:2330-5.

7 Lemp MA, Gold JB. The effects of extended wear hydrophilic contact lenses on the human corneal epithelium. Am f Ophthalmol 1986;101:274-7.

8 Mathers WD, Sachdev MS, Petroll M, et al. Morphologic effects of contact lens wear on the corneal surface. CLAO F 1992;18:49-52

9 Tsubota K, Yamada M. Corneal epithelial alterations induced by disposable contact lens wear. Ophthalmology 1992;99:1193-6.

10 Tsubota K, Hata S, Toda I, et al. Increase in corneal epithelial cell size with extended wear soft contact lenses depends on continuous wearing time. Br F Ophthalmol 1996;80:1447.

11 Papas E, Vajdic CM, Austen R, et al. High oxygen transmissibility soft contact lenses do not induce limbal hyperaemia. Curr Eye Res 1997;16:942-8.

12 Sweeney DF, Keay L, Jalbert I, et al. Clinical performance of silicone hydrogel lenses. Chapter 5, In: Sweeney DF ed. Silicone hydrogels - the rebirth of extended wear. Oxford: Butterworth-Heinemann, 2000:90-149.

13 Zhou J, Begley C, Wilson G. Composition of cells shed from the ocular surface. Optom Vis Sci 1996;73:65.

$14 \mathrm{Kolb}$ MJ, Bourne WM. Supravital staining of the corneal endothelium with acridine orange and ethidium bromide. Curr Eye Res 1986;5:485-94.

15 Laurent J, Wilson G. Size of cells collected from normal human subjects using contact lens cytology. Optom Vis Sci 1997;74:280-7.

16 O'Leary DJ, Madgewick R, Wallace J, et al. Size and number of epithelial cells washed from the cornea after contact lens wear. Optom Vis Sci 1998;75:692-6.

17 Tsubota K, Yamada M, Naoi S. Specular microscopic observation of normal human corneal epithelium. Ophthalmology 1992;99:89-94.

18 Lemp MA, Mathers WD. Corneal epithelial cell movement in humans. Eye 1989;3:438-5.

19 Polse KA. Tear flow under hydrogel lenses. Invest Ophthalmol Vis Sci 1979;18:409-13.

20 Wilson G. The effect of hypoxia on the shedding rate of the corneal epithelium. Curr Eye Res 1994;13:409-13.

21 Bonnano JA. Regulation of corneal epithelial intracellular pH. Optom Vis Sci 1991;61:682-6.

22 Fullard RJ, Carney LG. Human tear enzyme changes as indicators of the corneal response to anterior hypoxia. Acta Ophthalmol 1985;63:678-83.

23 Ichijima $\mathrm{H}$, Imaysau $M$, Ohashi $\mathrm{J}$, et al. Tear lactate dehydrogenase levels. A new method to assess the effects of contact lens wear in man. Cornea 1992;11:112-20.

24 Zhou J, Begley C, Wilson G. Diurnal variation and viability of corneal surface cells collected using a soft contact lens. Optom Vis Sci 1995;72:S91.

25 Ren H, Wilson G. Apoptosis in the corneal epithelium. Invest Ophthalmol Vis Sci 1996;37:1017-25.

26 Begley CG, Zhou J, Wilson G. Characterisation of cells shed from the ocular surface in normal eyes. Adv Exp Med Biol 1998;438:675-81. 